\title{
Mean winds, temperatures and the 16- and 5-day planetary waves in the mesosphere and lower thermosphere over Bear Lake Observatory $\left(42^{\circ} \mathrm{N}, 111^{\circ} \mathrm{W}\right)$
}

\author{
K. A. Day ${ }^{1}$, M. J. Taylor ${ }^{2}$, and N. J. Mitchell ${ }^{1}$ \\ ${ }^{1}$ Centre for Space, Atmospheric and Oceanic Science, Department of Electronic and Electrical Engineering, \\ The University of Bath, Bath, BA2 7AY, UK \\ ${ }^{2}$ Centre for Atmospheric and Space Science, Department of Physics, Utah State University, Logan, UT 84322, USA \\ Correspondence to: K. A. Day (k.a.day@bath.ac.uk)
}

Received: 22 August 2011 - Published in Atmos. Chem. Phys. Discuss.: 10 November 2011

Revised: 20 January 2012 - Accepted: 30 January 2012 - Published: 10 February 2012

\begin{abstract}
Atmospheric temperatures and winds in the mesosphere and lower thermosphere have been measured simultaneously using the Aura satellite and a meteor radar at Bear Lake Observatory $\left(42^{\circ} \mathrm{N}, 111^{\circ} \mathrm{W}\right)$, respectively. The data presented in this study is from the interval March 2008 to July 2011.

The mean winds observed in the summer-time over Bear Lake Observatory show the meridional winds to be equatorward at meteor heights during April-August and to reach monthly-mean velocities of $-12 \mathrm{~m} \mathrm{~s}^{-1}$. The mean winds are closely related to temperatures in this region of the atmosphere and in the summer the coldest mesospheric temperatures occur about the same time as the strongest equatorward meridional winds. The zonal winds are eastward through most of the year and in the summer strong eastward zonal wind shears of up to $\sim 4.5 \mathrm{~m} \mathrm{~s}^{-1} \mathrm{~km}^{-1}$ are present. However, westward winds are observed at the upper heights in winter and sometimes during the equinoxes. Considerable inter-annual variability is observed in the mean winds and temperatures.

Comparisons of the observed winds with URAP and HWM-07 reveal some large differences. Our radar zonal wind observations are generally more eastward than predicted by the URAP model zonal winds. Considering the radar meridional winds, in comparison to HWM-07 our observations reveal equatorward flow at all meteor heights in the summer whereas HWM-07 suggests that only weakly equatorward, or even poleward flows occur at the lower heights. However, the zonal winds observed by the radar and modelled by HWM-07 are generally similar in structure and strength.
\end{abstract}

Signatures of the 16- and 5-day planetary waves are clearly evident in both the radar-wind data and Aura-temperature data. Short-lived wave events can reach large amplitudes of up to $\sim 15 \mathrm{~m} \mathrm{~s}^{-1}$ and $8 \mathrm{~K}$ and $20 \mathrm{~m} \mathrm{~s}^{-1}$ and $10 \mathrm{~K}$ for the 16 and 5-day waves, respectively. A clear seasonal and shortterm variability are observed in the 16- and 5-day planetary wave amplitudes. The 16-day wave reaches largest amplitude in winter and is also present in summer, but with smaller amplitudes. The 5-day wave reaches largest amplitude in winter and in late summer. An inter-annual variability in the amplitude of the planetary waves is evident in the four years of observations. Some 41 episodes of large-amplitude wave occurrence are identified. Temperature and wind amplitudes for these episodes, $\mathrm{A}_{T}$ and $\mathrm{A}_{W}$, that passed the Student T-test were found to be related by, $\mathrm{A}_{T}=0.34 \mathrm{~A}_{W}$ and $\mathrm{A}_{T}=0.62 \mathrm{~A}_{W}$ for the 16- and 5-day wave, respectively.

\section{Introduction}

Ground-based meteor and MF radars are able to make continuous observations of winds in the Mesosphere and Lower Thermosphere (MLT) and have thus been extensively used to study the background winds and planetary waves of the MLT.

Previous ground-based observations have been made at Bear Lake Observatory (BLO) using an Imaging Doppler Instrument (IDI) to observe MLT mean winds and planetary waves. Berkey et al. (2001) presented results from February 1999 to April 2000. The mean meridional mean winds were found to be strongest at heights of $\sim 90 \mathrm{~km}$ in mid-winter reaching $\sim 15 \mathrm{~m} \mathrm{~s}^{-1}$. The zonal mean winds were found to 
be westward in late spring to early summer, reaching velocities of $\sim 25 \mathrm{~m} \mathrm{~s}^{-1}$. They also observed planetary waves, in particular a 16- and 5-6-day wave were evident.

Jones et al. (2003) compared four months of IDI measurements with those made by a meteor wind radar at the same site. It was concluded that there was overall a very good agreement between the two techniques. In addition, they noted the presence of long-period planetary waves in midlate February. Note this meteor radar was operated at BLO for a relatively short deployment and is not the same instrument now permanently sited there.

Roper and Berkey (2011) reported observations of mean winds, gravity waves and turbulence for the year 2000 made at BLO by the IDI. It was observed that the monthly-mean zonal winds maximised in summer at velocities of $\sim 35 \mathrm{~m} \mathrm{~s}^{-1}$ and reduced in the spring to velocities of $\sim-10 \mathrm{~m} \mathrm{~s}^{-1}$. The monthly-mean meridional winds were observed to be nearly continuously equatorward, except for a very short-lived region at the upper heights in April and May.

Further studies at similar latitudes in the USA and Canada include those of Luo et al. (2002a); Manson et al. (2004a), who used MF radars to investigate the planetary-wave field in the MLT and reported a strong seasonal variability.

The large-scale meridional motion of the middle atmosphere is described by the Brewer-Dobson circulation. In the stratosphere, planetary waves drive this circulation and transfer momentum by dissipation. They thus force the zonalmean flow by exerting an eddy drag. The decelerated zonalmean flow is accompanied by a change in the zonal-mean thermal structure, driving the circulation out of equilibrium and forcing a meridional circulation. In the mesosphere the meridional circulation is transferred into a pole-to-pole cell, where air is transported from the radiatively-heated summer pole to the cooled winter pole. Gravity waves are the primary driver of this mesospheric circulation, driving the mesosphere out of radiative equilibrium and reversing this temperature gradient leading to the well-known cold summer mesosphere phenomena. This circulation implies an intimate connection between the mean temperatures and the mean meridional winds of the MLT region. Many studies have addressed either the winds or the temperatures of the MLT in isolation. However, only a limited number of observational studies have investigated the connection between these winds and temperatures using simultaneous measurements.

It has been suggested that short-term perturbations in the meridional winds result in related short-term perturbations in temperature. For example, polar observations by Espy et al. (2003) revealed a clear correlation between meridional winds and temperatures over Rothera $\left(68^{\circ} \mathrm{S}, 68^{\circ} \mathrm{W}\right)$ and Halley $\left(76^{\circ} \mathrm{S}, 27^{\circ} \mathrm{W}\right)$ in a study made using an MF radar and $\mathrm{OH}$ rotational temperatures in Austral winters. Cho et al. (2011) reported meteor radar and $\mathrm{OH}$ airglow observations of meridional winds and temperatures in the Arctic MLT over Resolute Bay $\left(74^{\circ} \mathrm{N}, 95^{\circ} \mathrm{W}\right)$ and Esrange $\left(68^{\circ} \mathrm{N}, 21^{\circ} \mathrm{E}\right)$. They observed a positive correlation between the mean meridional winds and temperatures that is consistent with the large-scale circulation.

In contrast, Jacobi et al. (2007) measured meridional winds and temperatures in the MLT over Collm $\left(51^{\circ} \mathrm{N}\right.$, $\left.13^{\circ} \mathrm{E}\right)$ using a meteor radar. They considered time-scales of up to one month and reported that they did not observe a correlation between the meridional winds and temperatures in the summer, but they did observe a positive correlation in the winter.

Large meridional winds have been reported in the summertime MLT at polar-latitudes (e.g., Hocking, 2001; Sandford et al., 2010), mid-latitudes (e.g., Manson and Meek, 1987; Hall et al., 2008; Roper and Berkey, 2011) and equatoriallatitudes (e.g., Rajaram and Gurubaran, 1998; Kishore et al., 2000; Sharma et al., 2010).

At mid latitudes the characteristics of the meridional and zonal mean winds and temperatures of the MLT have been investigated using ground-based and satellite measurements. The meridional winds of the MLT are particularly important because they play a key role in transporting air from the summer polar MLT into the winter polar stratosphere, (e.g., Plane et al., 1999; Smith, 2004). Ultimately, diabatic subsidence transports some of the "meteor smoke" particles carried by this circulation down into the lower stratosphere, where they may influence ozone and, potentially, climate, (e.g., Plumb et al., 2002; Curtius et al., 2005).

Planetary waves are a major feature in the dynamics of the middle atmosphere. In the MLT they can reach large amplitudes and are important because they can modulate the amplitude of atmospheric tides (e.g., Teitelbaum and Vial, 1991; Mitchell et al., 1996; Palo et al., 1999; Pancheva et al., 2004), influence the transport and photochemistry of minor species (e.g., Kulikov, 2007), modulate the fluxes of gravitywave momentum that drives the planetary-scale circulation of the upper middle atmosphere (e.g., Forbes et al., 1991; Miyahara and Forbes, 1991; Thayaparan et al., 1995; Nakamura et al., 1997; Manson et al., 2003) and cause perturbations in temperatures that can modulate the occurrence of Polar Mesospheric Clouds (e.g., Espy and Witt, 1996; Merkel et al., 2003, 2008; Nielsen et al., 2010) and Polar Mesospheric Summer Echoes (e.g., Morris et al., 2009). A major component of the planetary-wave field in the MLT is the so-called normal modes that manifest as the 2-, 5-, 10- and 16-day planetary waves (e.g., Salby, 1981a,b).

Salby (1981a) suggested on theoretical grounds that the 16- and 5-day planetary waves are manifestations of the gravest symmetrical wavenumber 1 , westward-travelling Rossby wave. The periods of the 16- and 5-day wave has, in fact, been observed to be between about 12-20 days and 4-7 day, respectively (e.g., Williams and Avery, 1992; Luo et al., 2000, 2002a,b; Lieberman et al., 2003; Riggin et al., 2006; Belova et al., 2008; Day and Mitchell, 2010a,b). The 16-day wave has been reported to have wind amplitudes of up to about $\sim 15 \mathrm{~m} \mathrm{~s}^{-1}$ and temperature amplitudes reaching 
$\sim 10 \mathrm{~K}$ in the MLT (e.g. Williams and Avery, 1992; Forbes et al., 1995; Day and Mitchell, 2010b). The 5-day wave has been reported to have wind amplitudes of up to about $\sim 20 \mathrm{~m} \mathrm{~s}^{-1}$ and temperature amplitudes reaching $\sim 15 \mathrm{~K}$ in the MLT (e.g. Williams and Avery, 1992; Belova et al., 2008; Day and Mitchell, 2010a).

This study considers near-continuous observations of MLT winds and temperatures made over a 41-month interval using a meteor radar at BLO and the Aura Microwave Limb Sounder (MLS), respectively. The extended, simultaneous and complementary measurements allows insight into the important connect between atmospheric dynamics and the temperature of the MLT. The first focus of the study is to establish a climatology of mean winds over BLO at heights of about $80-100 \mathrm{~km}$ and to relate this to the seasonal variation in temperature. This is compared to the URAP and the HWM07 models. Secondly, a representative climatology of the 16and 5-day waves over BLO measured by simultaneous meteor radar winds and Aura MLS temperatures is presented. These complementary observations are used to investigate the relative magnitude of the wind and temperature perturbations caused by each wave. Note that here we will not consider the atmospheric tides, the 2-day wave or long-term variability of the mean winds and planetary waves. These subjects will be considered in subsequent publications.

\section{Data analysis}

The winds used in this study were measured by a meteor radar located at BLO, near Logan, Utah, in the USA $\left(42^{\circ} \mathrm{N}\right.$, $111^{\circ} \mathrm{W}$ ) installed in March 2008 . The radar is a standard allsky, SKiYMET VHF system operating at a radio frequency of $32.5 \mathrm{MHz}$, with a pulse repetition of $2144 \mathrm{~Hz}$ and a peak power of $6 \mathrm{~kW}$. The radar uses six crossed-element Yagi antenna, five receiving and one transmitting. The receiver antennas form an interferometer allowing the determination of meteor echo heights. More than $95 \%$ of meteor echoes are detected at heights between $80-100 \mathrm{~km}$. The radar typically records $\sim 4000$ meteors a day. Only underdense echoes are recorded. A more complete description of a very similar radar design can be found in Hocking et al. (2001).

The radar data were used to estimate zonal and meridional winds with a time step of $1 \mathrm{~h}$ at heights between $\sim 80$ $100 \mathrm{~km}$. This height range was divided into six independent height-gates of depth 5, 3, 3, 3, 3 and $5 \mathrm{~km}$. However, the vertical distribution of meteor echoes maximises at a height near $90 \mathrm{~km}$ and the meteor counts decrease strongly above and below this height. To allow for this, in each height gate the average meteor echo height was calculated yielding heights of $80.8,84.7,87.5,90.4,93.3$ and $97.1 \mathrm{~km}$ as the weighted mean height of the six height gates. The radar data set thus consists of hourly-spaced zonal and meridional winds in six height gates. The error on monthly-mean winds calculated using this data is generally less than $1 \mathrm{~m} \mathrm{~s}^{-1}$.
These local measurements of wind were complemented by estimates of temperature measured by Aura MLS. Aura MLS Version 2.2 Temperature Analysis was used in this study. MLS observations commenced from early August 2004 (Livesey et al., 2008). The data are recorded on 34 pressure levels, $316-0.001 \mathrm{hPa}(\sim 10-96 \mathrm{~km})$. The vertical resolution is $7-8 \mathrm{~km}$ at $316-100 \mathrm{hPa}, 4 \mathrm{~km}$ at $31-6.8 \mathrm{hPa}, 6 \mathrm{~km}$ at $1 \mathrm{hPa}$ and $9 \mathrm{~km}$ above $0.1 \mathrm{hPa}$. For this study the pressure levels were converted to approximate heights for comparisons with the meteor-radar measurements.

The standard product for temperature was taken for the Core retrieval ( $118 \mathrm{GHz}$ only) from $316-1.41 \mathrm{hPa}$ and from the Core+R2A (118 and $190 \mathrm{GHz}$ ) retrieval from 1$0.001 \mathrm{hPa}$. The temperature precision is $\sim \pm 1 \mathrm{~K}$ from $316-$ $0.1 \mathrm{hPa}$ and degrades to $\sim 3 \mathrm{~K}$ at $0.01 \mathrm{hPa}$ (Schwartz et al., 2008). The data are assigned a "flag" commenting on the quality of the data. The quality comment is computed from a $\chi^{2}$ statistic for all the radiances that are considered to have significantly affected the retrieved species and then normalised by dividing by the number of radiances. The quality flag is simply the reciprocal of this statistic. Data that have a quality flag of " 0 " are regarded as poor quality and therefore discarded.

\section{Results}

\subsection{Seasonal mean winds and temperatures}

This section presents the climatology of the mean winds and temperatures in the MLT over BLO. The climatological winds are then compared with the predicted winds from the UARS (URAP) and the HWM-07 models. To investigate the behaviour and characteristics of the background winds over BLO monthly-mean mean zonal and meridional winds were calculated for each month and height gate.

Firstly, we will consider the mean meridional winds and temperatures and examine how they are related. Figure 1 shows the monthly-mean meridional winds for each individual year and also a composite-year. Note that the monthlymean values may mask any short-term perturbations. Plotted below each meridional wind plot is the corresponding temperature plot. MLS temperatures were calculated as monthly-means for the height gates centered on $81,86,91$ and $97 \mathrm{~km}$ to allow a comparison with the meridional winds. The temperatures are means for a latitude/longitude "box" of $40-45^{\circ} \mathrm{N}, 90-120^{\circ} \mathrm{W}$ for the four height gates between $\sim 81-97 \mathrm{~km}$.

The figure reveals a clear seasonal cycle in which the meridional winds are equatorward (negative) in the summer and generally poleward (positive) in the winter. The meridional winds are generally equatorward from AprilSeptember at all heights observed by the radar. The flow is generally strongest at heights of $\sim 85 \mathrm{~km}$, regularly reaching velocities of $\sim-12 \mathrm{~m} \mathrm{~s}^{-1}$. In contrast, the winter-time 

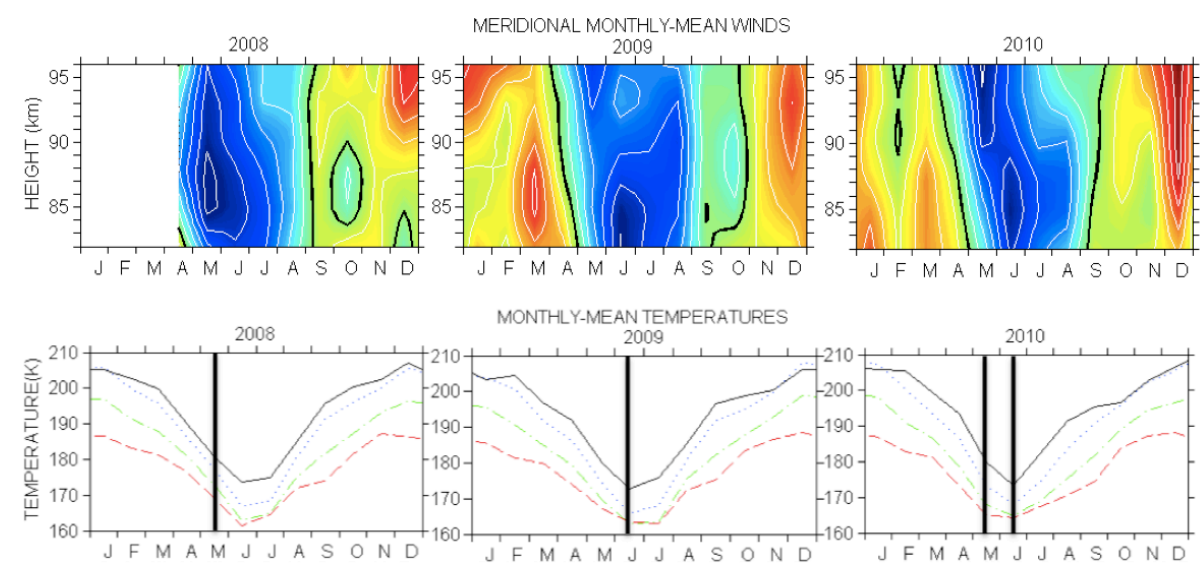

MONTHLYMEAN TEMPERATURES
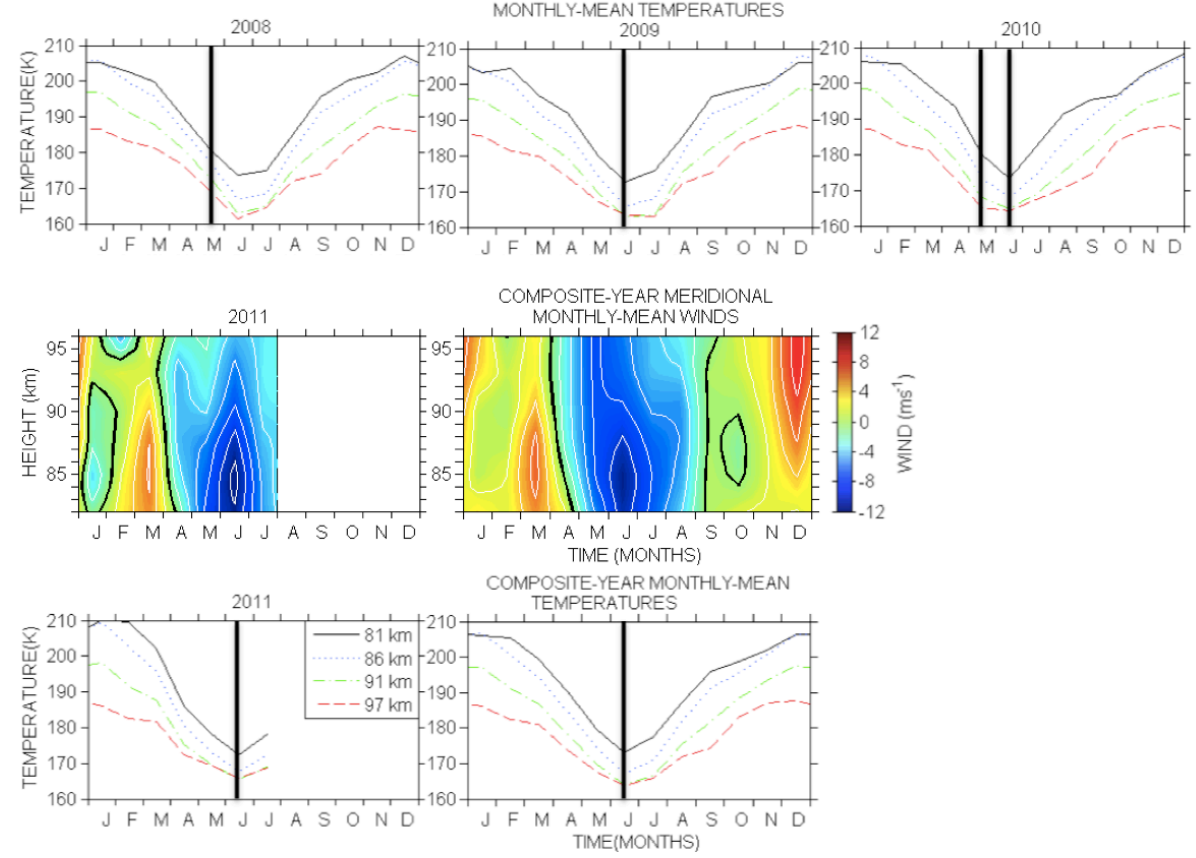

Fig. 1. Monthly-mean meridional winds over BLO and monthly-mean Aura MLS temperatures. The zero wind contour is indicated in black and the white contours are in steps of $2 \mathrm{~m} \mathrm{~s}^{-1}$. The temperatures are means for a latitude/longitude "box" of 40-45 $\mathrm{N}, 90-120^{\circ} \mathrm{W}$ for four height gates between on $\sim 81-97 \mathrm{~km}$. The black vertical lines on the temperature plots indicate time of minimum meridional winds.

flow is poleward and strongest in the upper heights. The strongest poleward flows are generally observed in early-mid winter reaching velocities of $\sim 12 \mathrm{~m} \mathrm{~s}^{-1}$ in most years. In the late winter the winds maximise again, but at slightly lower heights of $\sim 85 \mathrm{~km}$, reaching velocities of $\sim 6 \mathrm{~m} \mathrm{~s}^{-1}$. However, we should note that the use of monthly-means can hide short-term fluctuations in the mean winds.

The figure also reveals a high degree of inter-annual variability. For instance, if we consider the winds in summer we find that the strongest equatorward flows occurred in May in 2008 but in June in 2009, 2010 and 2011. We also note that the strongest equatorward flows peak at heights near $85 \mathrm{~km}$ in all years, except in 2010 when a region of strong flow existed at heights above $85 \mathrm{~km}$ in May. Further, the winter flow is not consistently poleward throughout the season, for example, in January 2011 the winds reverse and are equatorward reaching velocities of $-4 \mathrm{~m} \mathrm{~s}^{-1}$.

To examine the relationship between the meridional winds and temperatures, the temperature plots are marked with a vertical line where the strongest equatorward winds occurred. Two lines are shown for 2010 because the winds had two distinct episodes of maximum flow, one in May at about $95 \mathrm{~km}$ and the other in June at about $85 \mathrm{~km}$. It can be seen that the temperature minima in 2008 lags the corresponding meridional wind minima (i.e., time of strongest equatorward flow). However, the figure presents only monthly-mean winds and temperatures and so small differences in the time of strongest equatorward wind and temperature cannot be resolved.

To address this problem, a 16-day running mean of daily winds and temperatures was calculated. This was done to remove the effects of tides and planetary waves (if we did not use this smoothing we would get correlation caused by the coherent wind and temperature perturbations of any planetary waves). The correlation and lag was then calculated between the meridional winds and temperatures at $\sim 90 \mathrm{~km}$ during the months May-July using an auto-correlation. In 2008 the correlation coefficient reached a maximum of 0.27 at a lag of 18 days, in 2009 the correlation coefficient reached a maximum of 0.38 at a lag of 0 days, in 2010 the correlation coefficient reached a maximum of 0.60 at a lag of 1 day, in 2011 the correlation coefficient reached a maximum of 0.44 


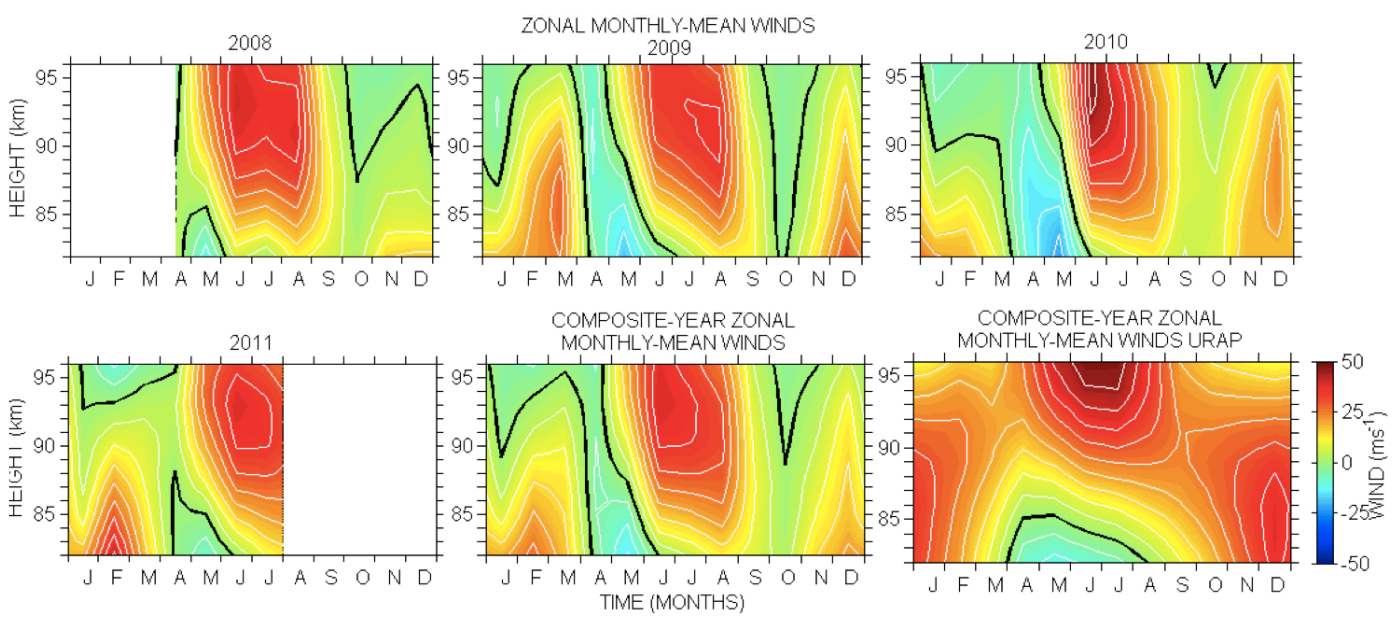

Fig. 2. Monthly-mean zonal winds and the zonally averaged composite-year monthly-mean zonal URAP winds over BLO. The zero wind contour is indicated in black and the white contours are in steps of $5 \mathrm{~m} \mathrm{~s}^{-1}$.

at a lag of 6 days. Finally, the composite-year correlation coefficient reached a maximum of 0.34 at a lag of 0 days. We conclude from this that the coldest temperatures tend to occur simultaneously with the strongest equatorward meridional winds. Finally, note that we did not observe a correlation between the strength of the mean meridional winds and temperatures.

Note that as a test we calculated the correlations of the winds and temperatures just using the daily means, i.e., without filtering in time to remove any planetary waves. In this case we observed multiple peaks, with the most dominate correction coefficients between $0.24-0.39$ for all years and zero lag. However, these correlations reflect the presence of planetary waves rather than any connect between the background winds and temperatures.

A similar monthly-mean wind analysis was used to produce Fig. 2, which shows the monthly-mean zonal winds for each individual year, a composite year and also the composite-year URAP zonally-averaged monthly-mean zonal winds.

The figure shows a well-defined seasonal cycle in monthly-mean zonal winds. Eastward flow occurs throughout the summer and through most of the winter except at the uppermost heights observed in winter and during late spring/early summer. The summer-time zonal winds maximise at heights of $\sim 93 \mathrm{~km}$ with wind velocities reaching up to $\sim 40 \mathrm{~m} \mathrm{~s}^{-1}$. Above and below these heights the wind velocities decrease. In the winter the zonal winds generally maximise at the lowest heights observed, at $\sim 83 \mathrm{~km}$ with winds reaching up to $\sim 30 \mathrm{~m} \mathrm{~s}^{-1}$. There is a minimum observed at the equinoxes. In two of the four years (2009 and 2010) the winds actually reverse at all heights near the spring equinox.

Some inter-annual variability is evident from Figs. 4 and 5 . However, with only a few years of date available it is hard to draw meaningful conclusions about inter-annual variability. We will thus restrict ourselves to only a limited quantitative discussion of inter-annual variability.

Firstly, considering the meridional winds in Fig. 4, it can be seen that in the summer-time the flow is generally equatorward from April to August. However, the strongest equatorward flow is not centered on the same month or height in each of the years presented. The strongest equatorward flow in 2010 is noteworthy as it has two peaks, one in May at heights of about $95 \mathrm{~km}$ and a second in June at heights of about $85 \mathrm{~km}$. The winter-time flow is generally poleward, but sometimes reverses. This can be seen in the winter of 2010/2011. The strength of the winter-time flow varies from year-to-year. For example, during the poleward flow of winter 2008/2009 there is a peak in December at heights above $95 \mathrm{~km}$, in March at heights about $86 \mathrm{~km}$.

Secondly, considering the zonal winds in Fig. 5, in the summer-time we find that the strongest eastward flows occur every June and peaked at heights of $\sim 93 \mathrm{~km}$. However, the duration of these strongly eastward winds varies from year-to-year. For example, in 2008, 2009 and 2011 the winds are strongly eastward from May-August and reach velocities of $\sim 35 \mathrm{~m} \mathrm{~s}^{-1}$, whereas in 2010 the winds are strongly eastward from May-July and reach rather stronger velocities of $\sim 45 \mathrm{~m} \mathrm{~s}^{-1}$. The spring equinoctial flow in 2009 and 2010 was strongly westward at all heights observed, reaching velocities of $\sim-20 \mathrm{~m} \mathrm{~s}^{-1}$. In contrast, in 2008 and 2011 the westward flow is significantly weaker or even absent around the spring equinox. In these two years the strongest winds reach only velocities of $\sim-10 \mathrm{~m} \mathrm{~s}^{-1}$ and are restricted to the lower heights, below $\sim 85 \mathrm{~km}$. 


\subsection{Comparison with URAP and HWM-07}

The URAP model uses measurements from the Upper Atmosphere Research Satellite (UARS), the High Resolution Doppler Instrument (HRDI) and the UK Met Office Stratospheric data assimilation system. See Swinbank and Ortland (2003) for more details. The data have been used here to produce a composite-year analysis of the monthly-mean zonally-averaged zonal winds. The monthly data are available from November 1991 to November 1999 at heights of $\sim 0-118 \mathrm{~km}$ and at latitudes of $-80-80^{\circ}$. Note that although this data set does not overlap in time with that of the radar and uses zonal rather than local averages, it nevertheless can be used to provide a useful "benchmark" comparison. The URAP model is used as it is an empirical model of global coverage and provides a comprehensive reference description of the stratosphere and mesosphere.

Comparing the zonal wind composite-year from our radar with the URAP model winds reveals some significant differences. The zonal winds are generally stronger in the URAP model. A striking difference is that the deep region of westward flow following the spring equinox is not well represented in the URAP model. Further, the winds in winter are significantly stronger in URAP than those observed and do not reverse at any height, whereas our observations suggest the winter zonal winds often reverse at heights between 90-95 km. We will consider possible explanations for this in Section 4. Considering the different years observed by the radar and the composite-year URAP monthly-mean zonal winds we see that they are most similar in the years 2008 and 2011 where, for example, there is no spring equinox reversal observed across the entire height range.

The HWM-07 model predicts both meridional and zonal winds using assimilated ground-based and satellite data. Full details of the model can be found in Drob et al. (2008). The model predicts results for a specified longitude, latitude and height. Here, the HWM-07 model has been used to estimate the meridional and zonal winds at $41.9^{\circ} \mathrm{N}$ and $111.4^{\circ} \mathrm{W}$, i.e., over BLO, for heights of $80-100 \mathrm{~km}$.

Figure 3 presents the meridional and zonal monthly-mean winds from the HWM-07 model. Considering the meridional winds, a comparison with the composite-year radar results of Fig. 1 reveals a general similarity in that the strongest equatorward winds occur in summer. However, there are a number of notable differences. In particular, the model shows equatorward winds present, at least at some heights, throughout the year (although some poleward flow does occur) whereas our observations show a clear seasonal reversal in meridional winds such that equatorward flow occurs at all heights from about April-August. Further, the model predicts poleward flows in winter of generally less than $2 \mathrm{~m} \mathrm{~s}^{-1}$, whereas our observations suggest rather faster flows of up to $\sim 8 \mathrm{~m} \mathrm{~s}^{-1}$. Finally, the model suggests the summer-time equatorward flow actually reverses heights below $\sim 80 \mathrm{~km}$,
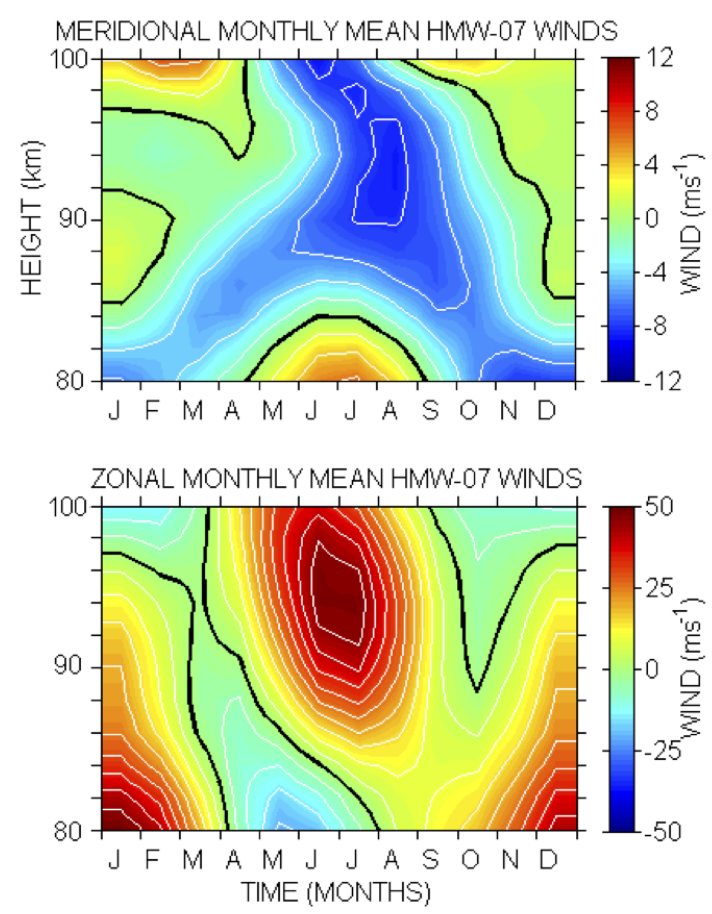

Fig. 3. Monthly-mean meridional and zonal winds over BLO $\left(41.9^{\circ} \mathrm{N}\right.$ and $\left.111.4^{\circ} \mathrm{W}\right)$, from the HWM-07 model. The zero wind line is indicated in black and the white lines indicate $5 \mathrm{~m} \mathrm{~s}^{-1}$ steps.

whereas our observation show that the flow is strongly equatorward even at the lowest heights observed.

Considering the zonal winds from the HWM-07 model, it can be seen that they are generally in good agreement with our composite-year zonal winds. However, a number of differences are again apparent. In particular, the wintertime zonal winds at the lower heights are much stronger in HWM-07 model than we observe. For instance, at the lowest heights considered the strongest winter-time winds reach almost $50 \mathrm{~m} \mathrm{~s}^{-1}$, whereas our observations indicate winds only about half that velocity. In the summer-time, the eastward winds in the model reach up to $\sim 50 \mathrm{~m} \mathrm{~s}^{-1}$ compared to our observations in which they reach up to $\sim 40 \mathrm{~m} \mathrm{~s}^{-1}$.

In summary we see that both the URAP and HWM-07 models predict stronger zonal winds in the winter than we observe at the lower heights. Further, although the HWM07 model predicts summer-time equatorward flows of similar velocity to those observed, it does not show the deep region of poleward flow evident over BLO.

\subsection{6- and 5-day planetary waves}

This section presents observations of the 16- and 5-day planetary waves over BLO. A particular focus will be observations of the waves made simultaneously in winds and temperatures. 


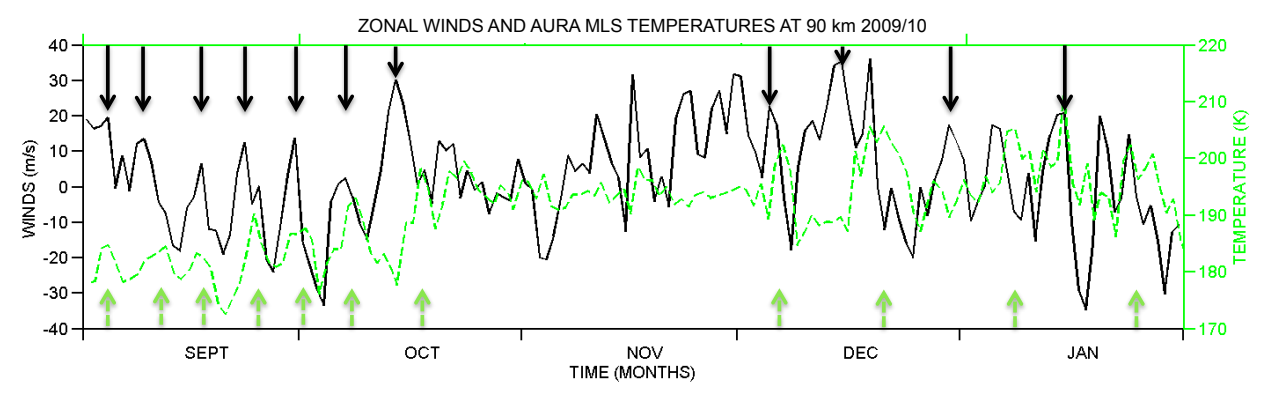

Fig. 4. The daily zonal winds and MLS temperatures at $\sim 90 \mathrm{~km}$ measured over BLO for the interval September 2009-January 2010. Wind maxima occurring at planetary wave periods ( $\sim 5$ and 16 days) are indicated by the arrows, wind on the top axis and temperature on the bottom axis.

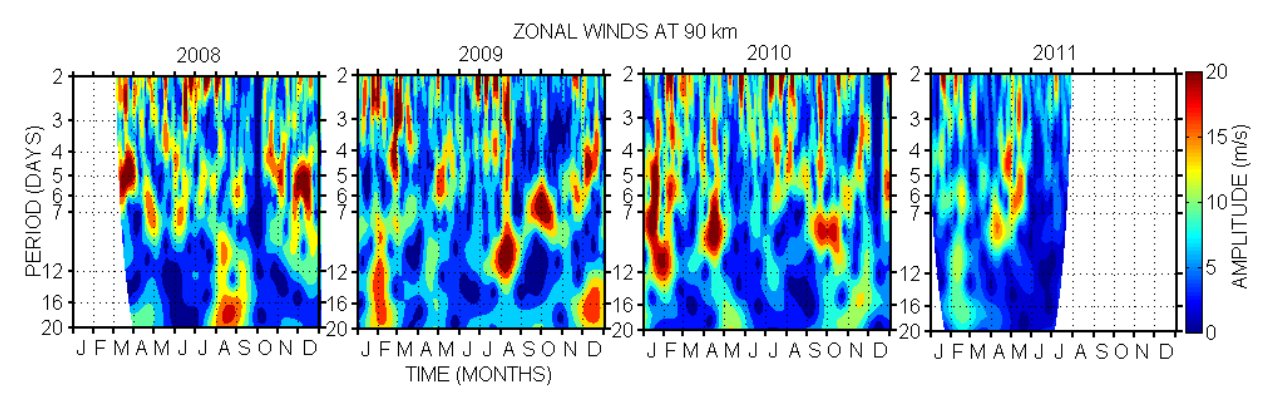

Fig. 5. A Wavelet analysis of hourly zonal wind amplitudes at heights of $\sim 90 \mathrm{~km}$, over BLO from March 2008 to July 2011.

The time-series of daily radar winds and MLS temperatures were first examined for oscillations that might be caused by planetary waves. Figure 4 presents an example of these winds and temperatures from the interval 1 September 2009 to 31 January 2010. It is evident from the figure that there are a number of intermittent oscillations in wind and temperature with periods of several days or more. Successive wind (top axis) and temperature (bottom axis) maxima are marked on the figure to highlight the oscillations. For example, there is an oscillation with the period of $\sim 6$ days and amplitude of order $\sim 10 \mathrm{~m} \mathrm{~s}^{-1}$ and $5 \mathrm{~K}$ in September (the period lengthening to $\sim 8$ days in October). There is also an oscillation of period $\sim 16$ days and amplitudes of order $\sim 15 \mathrm{~m} \mathrm{~s}^{-1}$ and $10 \mathrm{~K}$ in December and January, similarly marked on the figure. These periods are consistent with those reported for the "5-day wave" and the "16-day wave", respectively (e.g., Espy and Witt, 1996; Espy et al., 1997; Luo et al., 2002b; Lieberman et al., 2003; Riggin et al., 2006; Day and Mitchell, 2010a,b; Day et al., 2011).

To examine the evolution of these oscillations throughout the wind data, a wavelet analysis of the zonal-wind timeseries at a height of $\sim 90 \mathrm{~km}$ was performed and the results of this analysis are presented in Fig. 5. The analysis used a Morlet wavelet of non-dimensional wavenumber 6 , where the wavenumber is the number of oscillations within the envelope of the wavelet itself (Torrence and Compo, 1998). The figure shows "bursts" of wave activity occurring at different wave periods throughout the data set in a similar manner to those reported in observations of MLT winds (e.g., Manson et al., 2004b).

Wave amplitudes in the wavelet analysis can reach peak values of more than $20 \mathrm{~m} \mathrm{~s}^{-1}$. Particularly large-amplitude bursts include the 5- and 16-day wave bursts described above, i.e., in September-October 2009 (wave period 6-8 days) and December 2009 (wave period $\sim 16$ days) which have amplitudes of $\sim 13 \mathrm{~m} \mathrm{~s}^{-1}$ and $10 \mathrm{~m} \mathrm{~s}^{-1}$, respectively. Note that the 5-day wave appears to occur in bursts throughout the year in every year, whereas the 16-day wave is mainly present around both solstices.

To investigate the seasonal variability of the 16- and 5-day waves, the horizontal wind variance has been used as a proxy for wave activity. In this analysis, band-passed winds in each height gate for each month are used to calculate a variance value for the meridional and zonal components of the winds. in this case the time-series where band-passed between period limits of 12-20 days and 4-7 days, corresponding to the period ranges of the 16- and 5-day waves, respectively. These limits were chosen on the basis of the results presented above and because they are commonly used in studies of these two particular planetary waves (e.g. Williams and Avery, 1992; Luo et al., 2000, 2002a,b; Lieberman et al., 2003; Riggin et al., 2006; Belova et al., 2008; Day and Mitchell, 2010a,b).

By examining these variances as a function of height and time the seasonal and inter-annual variability of the 16- and 5 -day waves can be investigated. A similar analysis has been used in the studies of the 16-day and 5-day planetary waves 


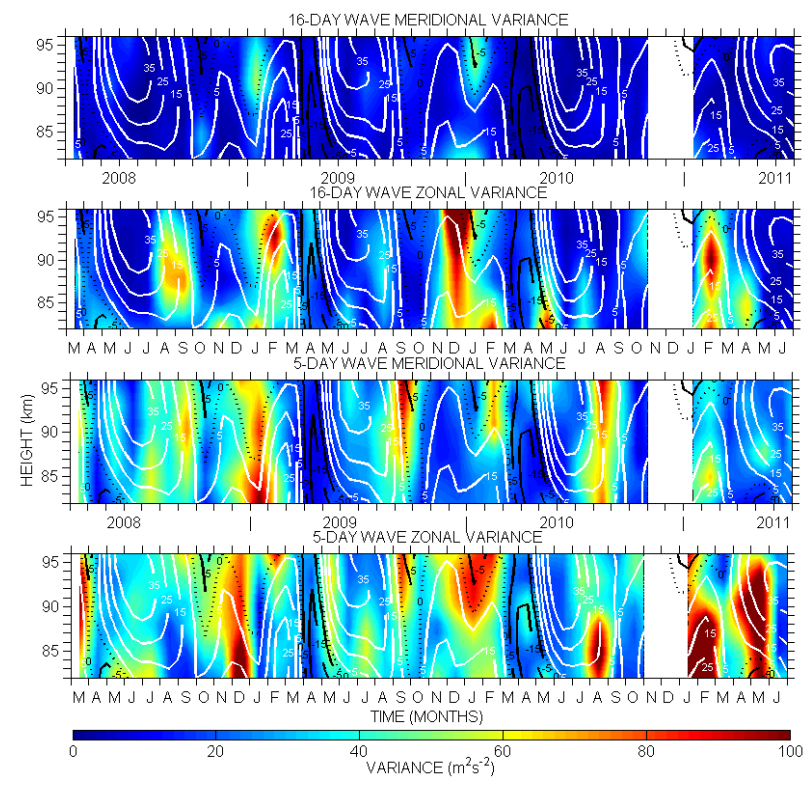

Fig. 6. Time-height contours (filled colour contours) of the monthly variance of winds band-passed between 12-20 and 4-7 days for the 16- and 5-day wave, respectively. Over BLO for both meridional and zonal components, 2008-2011. Also plotted are the monthlymean zonal winds. The zero-wind line is indicated by the heavy dashed line.

at polar latitudes (e.g., Day and Mitchell, 2010a,b). Note that for a constant amplitude oscillation, amplitude is equal to the square root of twice the variance. For example, a variance of $10 \mathrm{~m}^{2} \mathrm{~s}^{-2}$ corresponds to a wave amplitude of $4.5 \mathrm{~m} \mathrm{~s}^{-1}$, a variance of $50 \mathrm{~m}^{2} \mathrm{~s}^{-2}$ corresponds to a wave amplitude of $10 \mathrm{~m} \mathrm{~s}^{-1}$ and a variance of $100 \mathrm{~m}^{2} \mathrm{~s}^{-2}$ corresponds to a wave amplitude of $14.1 \mathrm{~m} \mathrm{~s}^{-1}$ etc.

Time-height contours of meridional and zonal monthly variances for all of the years of data available over BLO are presented in Fig. 6. The monthly-mean zonal winds for each year have been plotted over the top of the figure for that specific year to enable a comparison of the background winds and the level of 16- and 5-day wave variances.

Figure 6 shows that the 16-day wave generally maximises in winter-time throughout the height region observed, where it reaches variances of up to $\sim 100 \mathrm{~m}^{2} \mathrm{~s}^{-2}$. A secondary summer-time maximum is observed, where variances reach up to $\sim 30 \mathrm{~m}^{2} \mathrm{~s}^{-2}$ in 2009 and 2010 and $70 \mathrm{~m}^{2} \mathrm{~s}^{-2}$ in 2008. A minima is observed around the equinox. The summer-time 5-day wave is observed to be short-lived and localised in height, whereas the winter-time wave is generally longer-lived and occurs through the whole height region observed. The 5-day wave reaches maximum variances of up to $\sim 100 \mathrm{~m}^{2} \mathrm{~s}^{-2}$ in both summer-time and wintertime. Both waves usually display smaller variances around the equinoxes. The figure reveals a significant inter-annual variability of the waves in both the zonal and the meridional components.

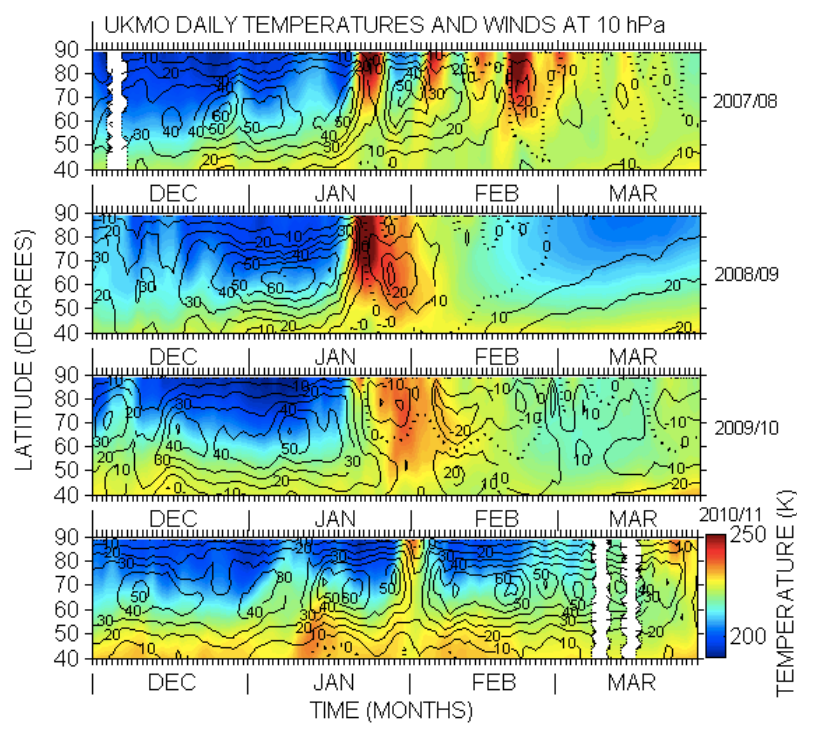

Fig. 7. Daily UKMO temperatures for the major SSW's in the Northern Hemisphere winters of 2004/2005 to 2010/2011. Also plotted are the UKMO daily zonal winds $\left(\mathrm{m} \mathrm{s}^{-1}\right)$ as contour lines.

In investigating the inter-annual variability of the waves the influence of Sudden Stratospheric Warming (SSW) events must be considered. For example, in 2009 there was a major SSW event and the following year a smaller but notable SSW event. SSWs are known to dampen planetarywave amplitudes about one month after the SSW has occurred. This has been reported in a number of studies, (e.g., Alexander and Shepherd, 2010; Day et al., 2011).

The UKMO stratospheric winds and temperatures at $10 \mathrm{hPa}$ have been used to characterise the SSW events during the time covered by this study. Figure 7 presents contours of these zonal-mean winds and temperatures for the four Northern Hemisphere winters considered here. From the figure it can be seen that in January 2009 and 2010 the zonal winds reversed and temperatures increased. A comparison between the observed SSW events of Fig. 7 and the planetary-wave variances of Fig. 6 reveals that stronger SSW events do appear to dampen planetary-wave variances about one month after the SSW. For example, in January 2009 there was a major SSW and in the mesosphere about one month later the planetary-wave variances were damped strongly. Similarly, in January 2010 there was a notable SSW and in the mesosphere about one month later the planetary-wave variances were again damped. In contrast, in January 2011 there was no major SSW and it is notable that in the mesosphere the planetary-wave variances were unaffected. This observation evidences the strong coupling between the layers of the atmosphere and the influence that major SSW have on mesospheric dynamics.

We will now compare our radar observations of the waves with observations of the waves in MLS temperature data. 

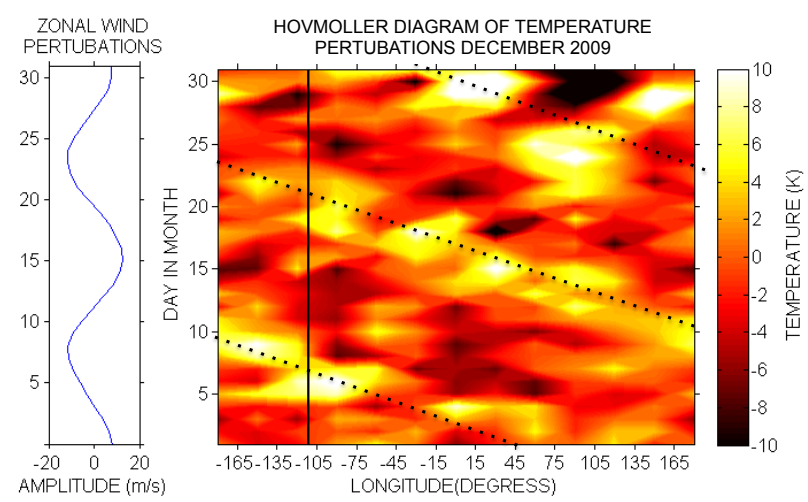

Fig. 8. On the right of the figure is the Hovmöller diagram of the Aura MLS temperature data in $30^{\circ}$ longitude bands for the month of December in 2009 , at $40-45^{\circ} \mathrm{N}$ and $\sim 90 \mathrm{~km}$. The black line shows the approximate location of BLO and the dashed line the wave phase fronts. On the left is the band-passed 16-day wave radar zonal winds for the same time and approximate height.
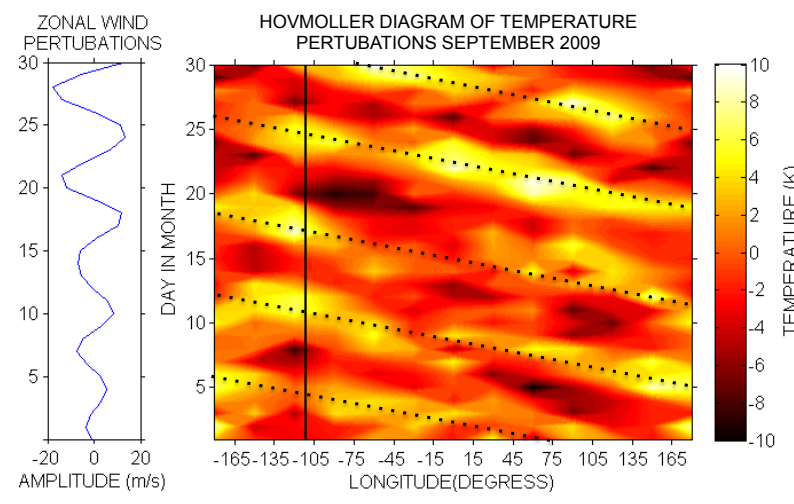

Fig. 9. On the right of the figure is the Hovmöller diagram of the Aura MLS temperature data in $30^{\circ}$ longitude bands for the month of September in 2009 , at $40-45^{\circ} \mathrm{N}$ and $\sim 90 \mathrm{~km}$. The black line shows the approximate location of BLO and the dashed line the wave phase fronts. On the left is the band-passed 5-day wave radar zonal winds for the same time and approximate height.

Figures 8 and 9 present data from December and September 2009 as examples of the wave signatures presented as Hovmöller diagrams. Other months showed similar wave signatures but are not shown here for reasons of space. Figures 8 and 9 also present the bandpassed zonal winds, using the same bandpass limits as used for Fig. 6. On each Hovmöller diagram a line indicating the longitude of BLO is shown.

Considering Fig. 8, the 16-day wave can be clearly seen in both the wind and temperature data. The wind amplitudes regularly reach up to $\sim 10 \mathrm{~m} \mathrm{~s}^{-1}$ and temperature amplitudes at the longitude of BLO regularly reach up to $\sim 5 \mathrm{~K}$. Considering Fig. 9, the 5-day wave can similarly be clearly seen in wind and temperature data. The wind amplitudes regularly reach up to $\sim 15 \mathrm{~m} \mathrm{~s}^{-1}$ and temperature amplitudes at

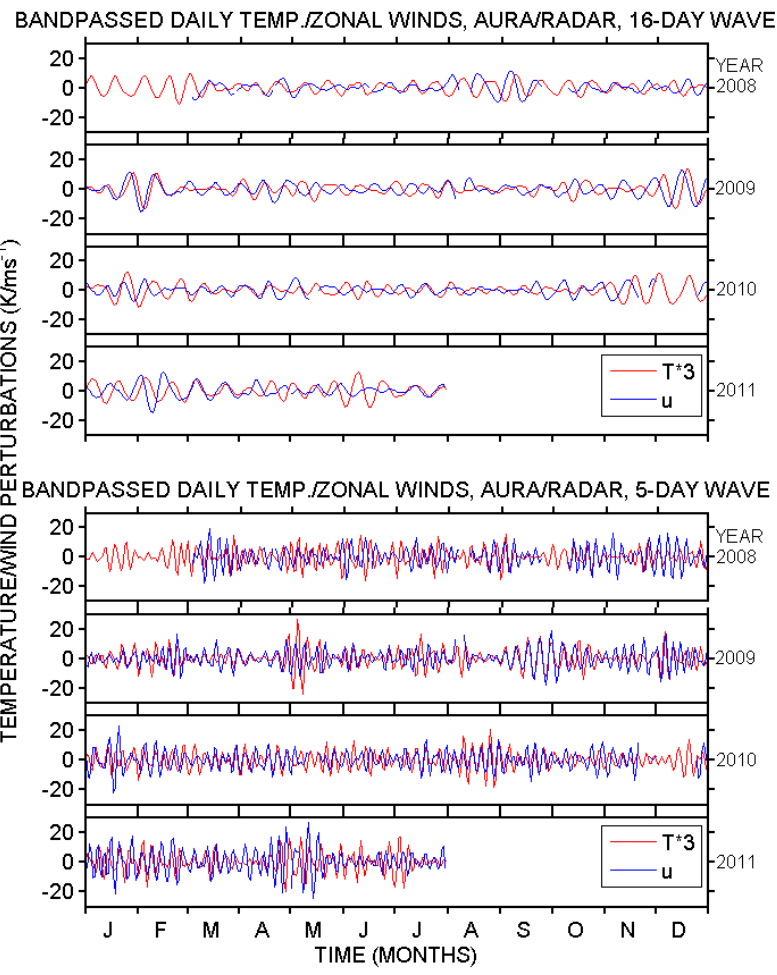

Fig. 10. Band-passed radar winds and Aura daily temperatures over BLO at $\sim 90 \mathrm{~km}$ for the years 2008-2011. Band-pass limits are for the wave periods of 12-20 days and 4-7 days for the 16- and 5-day wave, respectively. The Aura MLS data is from $40-45^{\circ} \mathrm{N}$ and 90 $120^{\circ} \mathrm{W}$. Note the temperatures have been multiplied by a factor of 3 to help comparison with the winds.

the longitude of BLO regularly reach up to $\sim 6 \mathrm{~K}$. In these observations we have interpreted the wind and temperature fluctuations with periods of 16 and 5 days as signatures of the 16- and 5-day planetary waves.

To examine the planetary waves in more detail, temperature and zonal wind time series were band-passed as previously described. The zonal winds were used because of the larger variances evident in Fig. 6. The results of this analysis are presented in Fig. 10. Note on the figure the temperatures have been multiplied by a factor of 3 to facilitate a simple by-eye comparison with the winds.

Considering both Figs. 6 and 10, the inter-annual variability of the waves are clearly evident. For example, the 5-day wave is known to have large amplitudes in the summer-time, but to be highly influenced by the background winds (e.g., Riggin et al., 2006; Belova et al., 2008; Day and Mitchell, 2010a). This may, in part, account for the inter-annual variability evident in our results. For example, in the summers of 2008 and 2009 the wave maximises at the middle and upper heights observed. In contrast, in the summer of 2010 the wave appears to extend to lower heights observed and maximises approximately one month earlier in the season. 


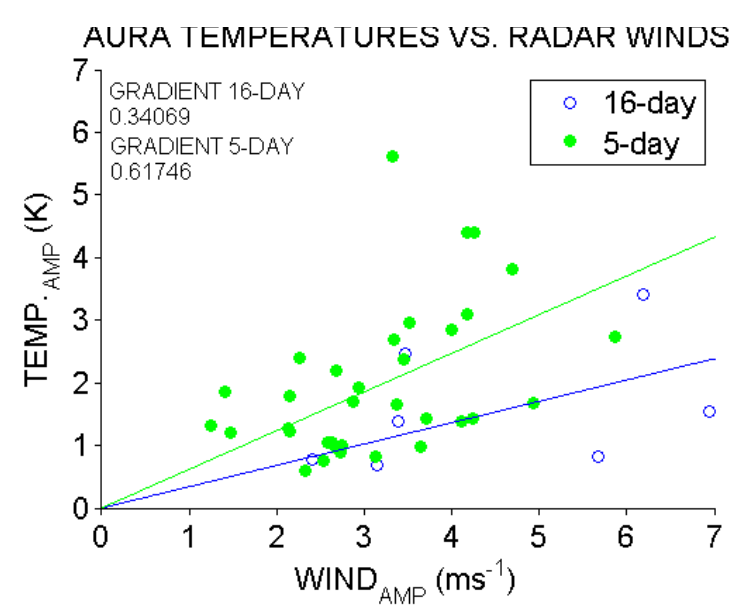

Fig. 11. Planetary-wave amplitudes measured by the meteor radar (WIND) and Aura MLS (TEMP) for large-amplitude wave events or "bursts".

Considering the band-passed winds and temperatures at $\sim 90 \mathrm{~km}$ presented in Fig. 10 it can be seen that in the case of both the 16- and 5-day waves, larger wind perturbations generally correspond to larger temperature perturbations. Note that here a height of $\sim 90 \mathrm{~km}$ is used as that is the height that most meteors are observed and the zonal winds are used as the 16-day wave is much stronger in this component of the winds. For each wave the correlation between the wind and temperature time series was calculated as a function of lag. In the case of the 16-day wave the correlation coefficient reached a maximum of 0.40 at a lag of 5 days with the winds leading the temperatures. This means for the 16day wave that the coldest temperatures occur when the winds are zero and reversing from eastward to westward. In the case of the 5-day wave the correlation coefficient reached a maximum of 0.22 at a lag of 2 days with the winds leading the temperatures. For completeness a similar analysis for the band-passed meridional winds and temperatures at $90 \mathrm{~km}$ was carried out. In the case of the 16-day wave the correlation coefficient reached a maximum of 0.38 at a lag of 1 day with the winds leading the temperatures. In the case of the 5-day wave the correlation coefficient reached a maximum of 0.36 at a lag of 2 days with the winds again leading the temperatures. These correlation coefficients suggest a small connection between wind and temperature.

To quantify the relationship between the zonal wind amplitudes and the temperature perturbation amplitudes of the two waves we considered episodes where the waves displayed large amplitude bursts. The bursts have been arbitrarily defined as a continuous event in which the wind amplitude exceeded $5 \mathrm{~m} \mathrm{~s}^{-1}$ for a duration of more than one cycle. Bursts were only used if a Student T-test showed the wind and temperature flutuations to be statistically related above a $90 \%$ confidence level.

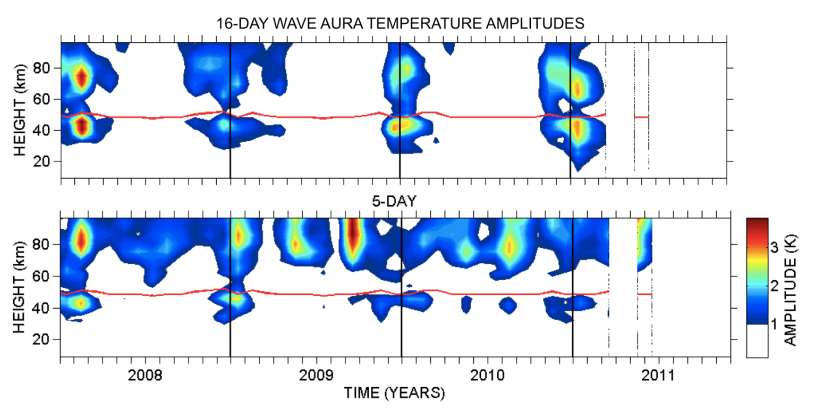

Fig. 12. Time-height contours of monthly-mean temperature amplitudes from 2008-2011 for the 16- and 5-day waves at a latitude of $35-45^{\circ} \mathrm{N}$. Also plotted is the stratopause height (red contour line).

Figure 11 presents the results of this analysis for both waves. A least-squares straight-line fit was forced through zero to these data suggests that the temperature and wind amplitudes, $\mathrm{A}_{T}$ and $\mathrm{A}_{W}$, respectively are related by $\mathrm{A}_{T}=0.34 \mathrm{~A}_{W}$ for the 16-day wave and $\mathrm{A}_{T}=0.62 \mathrm{~A}_{W}$ for the 5-day wave (i.e., for the 16-day wave a $1 \mathrm{~m} \mathrm{~s}^{-1}$ wind amplitude corresponds to a temperature perturbation amplitude of $0.34 \mathrm{~K})$. The least-squares straight-line fit was forced though $(0,0)$ because it was assumed that zero wind perturbation corresponds to zero temperature perturbation. The error analysis on the fit for the 16- and 5-day wave reveals $r^{2}$ values of 0.1132 and 0.2055 , respectively. Note that a similar analysis in which the least-squares straight-line fit was not required to pass through the origin yield gradients of 0.23 and 0.53 for the 16- and 5-day wave respectively.

A similar analysis was used to quantify the relationship between the meridional wind and temperature perturbations (the figures are not shown for reasons of space). For the 16day wave there were only three points that met the criteria and passed the Student T-test so the analysis was not taken further. However, for the 5-day wave there were 41 points that passed and a relationship of $\mathrm{A}_{T}=0.65 \mathrm{~A}_{W}$ and an error $r^{2}$ value of 0.2125 . Note that a similar analysis in which the least-squares straight-line fit was not required to pass through the origin yielded a gradient of 0.62 .

Finally, we analysed the Aura MLS temperatures using the least-square fitting method of Wu et al. (1995) to calculate wave amplitudes. This method has been used by a number of other studies (e.g., Limpasuvan et al., 2005; Baumgaertner et al., 2008; Limpasuvan and Wu, 2009; McDonald et al., 2011; Day et al., 2011). The uncertainty in the wave amplitude estimated using this method is usually $\pm 0.6 \mathrm{~K}$ or smaller, e.g., Day et al. (2011). In this analysis the temperature data were sorted into $10^{\circ}$ latitude bands and the leastsquares fitting of a westward-propagating zonal wavenumber 1 wave was applied to the monthly data within each latitude band. The data were then gridded into 31 latitude bins, in steps of $5^{\circ}$. Wave periods of 12-20 and 4-7 days were fitted in hourly steps. The largest amplitude signal within this 
period range was then identified as the 16- and 5-day day wave, respectively, for a particular latitude band and month. For each height and latitude bin we thus produced a time series of the temperature amplitude of the waves. Here, we have used this analysis to determine the temperature amplitudes of the 16- and 5-day waves within a latitude band of $35-45^{\circ} \mathrm{N}$, assuming both waves to be westward-propagating zonal-wavenumber 1 features. In each case, the zonallyaveraged amplitudes were calculated as monthly means.

Figure 12 presents the zonal-mean monthly wave temperature amplitudes calculated by this analysis. Figure 12 reveals the same general seasonal cycle for the 16- and 5-day waves as is observed in winds over BLO in the upper mesosphere (Fig. 6).

Figure 12 reveals that the 16-day wave reaches largest amplitudes of $\sim 4 \mathrm{~K}$ in winter at heights near $\sim 80 \mathrm{~km}$ but also has a second maximum at $\sim 45 \mathrm{~km}$. This was also observed by e.g., Day et al. (2011) in their study of the 16-day wave. Figure 12 shows the 5-day wave to maximise in winter and late summer with amplitudes of up to $\sim 4 \mathrm{~K}$ at heights of $\sim 90 \mathrm{~km}$. A winter-time maximum is also observed near the stratopause with amplitudes of up to $\sim 3 \mathrm{~K}$ at heights of $\sim 45 \mathrm{~km}$.

Comparing these satellite observations with our radar observations, the winter-time and summer-time signatures for the 16- and 5-day waves, can be seen to be clearly represented in both the satellite and radar observations. However, the satellite observations of Fig. 12 reveal that the summer-time 5-day wave only reaches significant amplitudes at heights above $\sim 70 \mathrm{~km}$ and so does not extend to heights much lower than those observed by the radar. Figure 12 also shows that the 16-day wave does not reach monthly-mean amplitudes of greater than $1 \mathrm{~K}$ in summer at these latitudes.

\section{Discussion}

The seasonal pattern of zonal and meridional winds we report here is in good general agreement with earlier observations made at BLO (e.g., Berkey et al., 2001; Jones et al., 2003; Roper and Berkey, 2011) and other mid-latitude Northern Hemisphere observations (e.g., Manson et al., 2004a). However, some differences are apparent. The meridional mean winds reported here are stronger than those reported for the year 2000 in the IDI study of Roper and Berkey (2011), who did not observe the equinoctial reversals evident in Fig. 1. These differences may be a consequence of the different years of observation or may result from instrument biases between meteor radar and IDI.

The seasonal variability of the mean winds and temperatures presented in this study agree very well with the simple concepts of the Brewer-Dobson circulation. The seasonal reversal of the meridional winds in summer to an equatorward flow is accompanied by a decline towards the lowest temperatures and the lowest temperatures of all occur on or up to 18 days after the strongest equatorward winds have been established. Further, the strongest shears in the zonal winds occur at the same time as the strongest equatorward winds. This general pattern of observation agrees well with other groundbased observations made by radar and/or lidar at middle latitudes in the Northern Hemisphere, (e.g., Manson and Meek, 1987; Portnyagin et al., 2004; Jacobi et al., 2007; Hall et al., 2008; Roper and Berkey, 2011).

A particularly interesting comparison can be made between our results and the composite-year results reported by Yuan et al. (2008) who used a Na lidar at the nearby site of Fort Collins, Colorado $\left(41^{\circ} \mathrm{N}, 105^{\circ} \mathrm{W}\right)$ to measure winds and temperatures in the MLT from 2002-2006. They observed slightly stronger equatorward meridional winds in summer, peaking at a velocity of $\sim-17 \mathrm{~m} \mathrm{~s}^{-1}$ compared to the $\sim-12 \mathrm{~m} \mathrm{~s}^{-1}$ that we observed. However, the height at which the strongest equatorward flow occurs is in good agreement, some $\sim 85 \mathrm{~km}$ in our study and $\sim 86 \mathrm{~km}$ in theirs. Yuan et al. (2008) observed the late summer reversal to poleward winds occurred later in the season at greater heights in their lidar data. However, our observations show the reversal to occurs almost simultaneously at all heights.

The seasonal pattern of temperatures reported by Yuan et al. (2008) is very similar to that reported here. For example, in the summer-time they observed temperatures to be $\sim 167 \mathrm{~K}$ at heights of $\sim 84 \mathrm{~km}$. Our observations are similar, $173 \mathrm{~K}$ at $\sim 81 \mathrm{~km}$ and $167 \mathrm{~K}$ at $\sim 86 \mathrm{~km}$. The seasonal pattern they report for the zonal winds is also in good argument with ours with regards with the timing of the actual wind reveals and the winds velocities, generally agreeing to within $10 \mathrm{~m} \mathrm{~s}^{-1}$. An observed lag between the strongest mean meridional winds and the lowest mean temperatures was also evident in the lidar observations of Yuan et al. (2008).

Comparing the radar winds with the URAP and the HWM07 models reveals a number of notable differences. Specifically, URAP presents zonal winds as being much more eastwards than in our observations for all months at all heights except for heights of $82-85 \mathrm{~km}$ in June-August, where URAP presents them as being weaker.

An explanation for these differences may be that that the URAP winds were modelled using data from 1991-1999 and therefore some differences may be explained by changes in the general circulation in the MLT occurring over decadal time scales. Further, URAP presents zonally-averaged zonal winds and so any longitudinal structure in the winds may cause differences when comparisons are made with our localised ground-based measurements. Such structure may be caused by stationary planetary waves. Finally, differences may also arise from measurement biases existing between the meteor radar and the satellite instrument used in the model, (the High Resolution Doppler Imager, HRDI, (e.g., Portnyagin et al., 2004)).

HWM-07 models the equatorward (negative) meridional winds in the summer-time to be weaker than we observed and 
to occupy a smaller height range. In contrast, the zonal winds predicted by the model are in quite good agreement with our observations. These differences may arise for similar reasons to those suggested in the case of URAP.

Our observations of the 16- and 5-day waves reveal that both waves have a winter maxima and equinoctial minima. In winter, both waves can be present throughout the height range observed by the radar. This observation is consistent with the simple interpretation that the waves have ascended from sources in the lower atmosphere of the winter hemisphere, through the eastward winds of the winter stratosphere, to the MLT. In the case of both waves, the observed amplitudes are broadly consistent with those reported in other studies made at middle latitudes (e.g., Luo et al., 2000; Lieberman et al., 2003; Mitchell et al., 1999; Day et al., 2011).

Further, in the radar observations, both the 16- and 5-day planetary waves display secondary maxima in the summer at heights above the regions of strong westward wind in the mesosphere, which would prevent the waves from having propagated there directly from the underlying lower atmosphere (Charney and Drazin, 1961). Note that the summer maximum of the 16-day wave is not evident in the satellite observations, probably because its amplitude is too small.

In the case of the 16-day wave, the presence of the wave in the summer-time MLT has been reported in a number of studies made at mid- and high-latitudes (e.g., Williams and Avery, 1992; Luo et al., 2000; Espy et al., 1997; Mitchell et al., 1999; Day and Mitchell, 2010b; Day et al., 2011). Two mechanisms have been advanced to explain these observations.

In the first mechanism, the 16-day wave in the summertime lower stratosphere is proposed to modulate the field of ascending gravity waves such that when they dissipate at MLT heights the resulting modulated momentum flux and zonal wind acceleration excites the wave in situ (Williams and Avery, 1992). Modelling support for this hypothesis is provided by the study of Smith (2003), who reported that significant planetary-wave amplitudes were excited in the MLT by this process, at least in the case of stationary planetary waves.

The second mechanism proposes that the 16-day wave is ducted across the equator from the winter hemisphere, above the heights where the strong westerly winds of the summer hemisphere prohibit propagation. The plausibility of this mechanism has been demonstrated in modelling studies (e.g., Miyahara and Forbes, 1991; Forbes et al., 1995) and experimental studies have sought to determine if any such equator-crossing wave is modulated in amplitude by the Quasi-Biennial Oscillation - although with sometimes contradictory conclusions (e.g., Espy et al., 1997; Jacobi et al., 1998; Jacobi, 1998; Hibbins et al., 2009; Day et al., 2011).

We should note that the 16-day wave in the summer MLT is observed to be generally confined to high latitudes and so the small amplitudes observed over BLO in summer may also be a consequence of this site's location towards the equatorward edge of the region of significant wave amplitude (e.g., Day et al., 2011).

In the case of the 5-day wave, the wave amplitudes in summer are slightly larger than those of the 16-day wave. Riggin et al. (2006) observed a particularly strong 5-day wave event using TIMED/SABER data and suggested that this wave was ducted from the winter hemisphere to the summer hemisphere, where it was then amplified by baroclinic instability. Belova et al. (2008) considered satellite and ground-based observations to suggest that upward propagation from the stratosphere in the summer-hemisphere, cross-equator propagation from the winter hemisphere or in-situ excitation as a result of the baroclinic instability may all be capable of exciting the 5-day wave in the summertime MLT. It thus seems that cross-equatorial ducting may well explain the 5day planetary wave observed over BLO in summer, but that other mechanisms may also contribute.

Throughout the period of observation, both in summer and winter, the two planetary waves display a high degree of intermittency, with significant fluctuations in both amplitude and period occurring on time scales of a few days (e.g., Fig. 5). These fluctuations appear to be a universal feature of planetary waves in the MLT, regardless of year or season (e.g., Luo et al., 2002a,b; Manson et al., 2004b; Day and Mitchell, 2010b). The origin of such intermittency has been suggested to lie in the sensitivity of planetary-wave propagation to the relative magnitudes of the zonal jets in the summer and winter hemispheres, which can vary on relatively short timescales (e.g., Hagan et al., 1993). This intermittency leads to a high degree inter-annual variability observed in the waves.

\section{Conclusions}

The monthly-mean mean zonal and meridional winds in the MLT over BLO reveal a clear seasonal cycle. The mean meridional wind is usually poleward throughout the year except for a region of strong equatorward flow occurring in the summer. The coldest temperatures generally occur at, or up to about 18 days after, the time at which the equatorward winds of the summer-time are at their strongest. The mean zonal winds are eastward throughout much of the year but do display some westward flow in winter and around the equinoxes. The observed eastward winds in winter are significantly weaker than those suggest by the URAP and the HWM-07 models. This maybe a result of measurement biases or, more likely, stationary planetary waves in the winter MLT.

The 16- and 5-day planetary waves reach large amplitudes in winter and are present in summer. The planetary-waves are evident in both wind and temperature measurements and the largest amplitudes in wind and temperature generally occur simultaneously. The amplitudes display a high 
degree of intermittence and inter-annual variability, which is probably driven by on fluctuations of the background winds. The presence of the waves in summer requires that they have either an in situ source or have been ducted across the equator from the winter hemisphere.

Edited by: A. J. G. Baumgaertner

\section{References}

Alexander, S. P. and Shepherd, M. G.: Planetary wave activity in the polar lower stratosphere, Atmos. Chem. Phys., 10, 707-718, doi:10.5194/acp-10-707-2010, 2010.

Baumgaertner, A. J. G., McDonald, A. J., Hibbins, R. E., Fritts, D. C., Murphy, D. J., and Vincent, R. A.: Short-period planetary waves in the Antartic middle atmosphere, J. Atmos. Solar-Terr. Phys., 70, 1336-1350, 2008.

Belova, A., Kirkwood, S., Murtagh, D., Mitchell, N. J., Singer, W., and Hocking, W.: Five-day planetary waves in the middle atmosphere from Odin satellite data and ground-based instruments in Northern Hemisphere summer 2003, 2004, 2005 and 2007, Ann. Geophys., 26, 3557-3570, doi:10.5194/angeo-263557-2008, 2008.

Berkey, F. T., Fish, C. S., and Jones, G. O. L.: Initial observations of mesopsheric winds using IDI radar measurements at the Bear Lake Observatory, Geophys. Res. Letts., 28, 135-138, 2001.

Charney, J. G. and Drazin, P. G.: Propagation of planetary-scale disturbances from lower into the upper atmosphere, J. Geophys. Res., 66, 83-109, 1961.

Cho, Y.-M., Shepherd, G. G., Shepherd, M. G., Hocking, W. K., Mitchell, N. J., and Won, Y.-I.: A study of temperature and meridional wind relationships at high northern latitudes, J. Atmos. Solar-Terr. Phys., 73, 936-943, 2011.

Curtius, J., Weigel, R., Vossing, H.-J., Wernli, H., Werner, A., Volk, C.-M., Konopka, P., Krebsbach, M., Schiller, C., Roiger, A., Schlager, H., Dreiling, V., and Borrmann, S.: Observations of meteoric material and implications for aerosol nucleation in the winter Arctic lower stratosphere derived from in situ particle measurements, Atmos. Chem. Phys., 5, 3053-3069, doi:10.5194/acp-5-3053-2005, 2005.

Day, K. A. and Mitchell, N. J.: The five-day wave in the Arctic and Antartic mesosphere and lower thermomsphere, J. Geophys. Res., 115, D01109, doi:10.1029/2009JD012545, 2010a.

Day, K. A. and Mitchell, N. J.: The 16-day wave in the Arctic and Antarctic mesosphere and lower thermosphere, Atmos. Chem. Phys., 10, 1461-1472, doi:10.5194/acp-10-1461-2010, $2010 \mathrm{~b}$.

Day, K., Hibbins, R., and Mitchell, N.: Aura MLS observations of the westward-propagating $s=1,16$-day planetary wave in the stratosphere, mesosphere and thermosphere, Atmos. Chem. Phys., 11, 4149-4161, doi:10.5194/acp-11-4149-2011, 2011.

Drob, D. P., Emmert, J. T., Crowley, G., Picone, J. M., Shepherd, G. G., Skinner, W., Hays, P., Niciejewski, R. J., Larsen, M., She, C. Y., Meriwether, J. W., Hernandez, G., Jarvis, M. J.and Sipler, D. P., Tepley, C. A., O’Brien, M. S., Bowman, J. R., Wu, Q., Murayama, Y., Kawamura, S., Reid, I. M., and Vincent, R. A.: An empirical model of the Earth's horizontal wind fields: HWM07, J. Geophys. Res., 113, A12304, doi:10.1029/2008JA013668, 2008.
Espy, P. J. and Witt, G.: Observation of a quasi 16-day oscillation in the polar summer mesospheric temperature, Geophys. Res. Lett., 23, 1071-1074, 1996.

Espy, P. J., Stegman, J., and Witt, G.: Interannual variations of the quasi-16-day oscillation in the polar summer mesospheric temperature, J. Geophys. Res., 102, 1983-1990, 1997.

Espy, P. J., Hibbins, R. E., Jones, G. O. L., Riggin, D. M., and Fritts, D. C.: Rapid, large-scale temperature changes in the polar mesosphere and their relationship to meridional flows, Geophys. Res. Lett., 30, 1240, doi:10.1029/2002GL016452, 2003.

Forbes, J. M., Jun, G., and Miyahara, S.: On the interactions between gravity waves and the diurnal propagating tides, Planetary and Space Science, 39, 1249-1257, 1991.

Forbes, J. M., Hagan, M. E., Miyahara, S., Vial, F., Mason, A. H., Meek, C. E., and Portnyagin, Y. I.: Quasi 16-day oscillation in the mesosphere and lower thermosphere, J. Geophys. Res., 100, 9149-9163, 1995.

Hagan, M. E., Forbes, J. M., and Vial, F.: Numerical Investigation of the Propagation of the Quasi 2-Day Wave into the Lower Thermosphere, J. Geophys. Res., 98, 193-205, 1993.

Hall, C. M., Meek, C. E., Manson, A. H., and Nozawa, S.: Turbopause determination, climatology, and climatic trends using medium frequency radars at $52^{\circ} \mathrm{N}$ and $70^{\circ} \mathrm{N}$, J. Geophys. Res., 113, D13104, doi:10.1029/2008JD009938, 2008.

Hibbins, R. E., Jarvis, J. M., and Ford, E. A. K.: Quasi-biennial oscillation influence on long-period planetary waves in the Antarctic upper mesosphere, J. Geophys. Res., 114, D09109, doi:10.1029/2008JD011174, 2009.

Hocking, W. K.: Middle atmosphere dynamical studies at Resolute Bay over a full representative year: mean winds, tides, and special oscillations, Radio Sci., 36, 1795-1822, 2001.

Hocking, W. K., Kelley, M., Roger, R., Brown, W. O. J., Moorcroft, D., and St Maurice, J. P.: Resolute Bay VHF radar: A multipurpose tool for studies of tropospheric motions, middle atmosphere dynamics meteor physics and ionospheric physics, Radio Sci., 36, 1839-1857, 2001.

Jacobi, C.: The Quasi 16-day Wave in the Summer Midlatitude Mesopause Region and its Dependence on the Equatorial QuasiBiennial Oscillation, Report of the LIM and the IFT9, Leipzig, Germany, 117-129, 1998.

Jacobi, C., Schminder, R., and Kürschner, D.: Long-period (12-25 days) oscillations in the summer mesopause region as measured at Collm $\left(52^{\circ} \mathrm{N}, 15^{\circ} \mathrm{E}\right)$ and their dependence on the equatorial quasi-biennial oscillation, Atmos. Phys., 1, 461-464, 1998.

Jacobi, C., Frohlich, K., Viehweg, C., Stober, G., and Kurschner, D.: Midlatitude mesopshere/lower thermosphere meridional winds and temperatures measured with meteor radar, Advances Space Res., 39, 1278-1283, 2007.

Jones, G. O. L., Berkey, F. T., Fish, C. S., Hocking, W. K., and Taylor, M. J.: Validation of imaging Doppler interferometer winds using meteor radar, Geophys. Res. Letts., 30, 1743, doi:10.1029/2003GL017645, 2003.

Kishore, P., Namboothiri, S. P., and Igarash, K.: Study of mesosphere lower thermosphere (MLT) mean winds over Yamagawa (31.2 N, 130.6 E) during 1996-1998, J. Geophys. Res., 105, 24863-24870, 2000.

Kulikov, M.: Theoretical investigation of the influence of a quasi-2-day wave on nonlinear photochemical oscillations in the mesopause region, J. Geophys. Res.-Atmos., 12, D02305, 
doi:10.1029/2005JD006845, 2007.

Lieberman, R. S., Riggin, D. M., Franke, S. J., Manson, A. H., Meek, C., Nakamura, T., Tsuda, T., Vincent, R. A., and Reid, I.: The 6.5-day wave in the mesosphere and lower thermosphere: Evidence for baroclinic/barotropic instability, J. Geophys. Res., 108, 4640, doi:10.1029/2002JD003349, 2003.

Limpasuvan, V. and Wu, D. L.: Anomalous two-day wave behavior during the 2006 austral summer, Geophys. Res. Letts., 36, doi:10.1029/2008GL036,387, 2009.

Limpasuvan, V., Wu, D. L., Schartz, M. J., Wates, J. W., Wu, Q., and Killeen, T. L.: The two-day wave in ESO MLS temperature and wind measurements during 2004-2005 winter, Geophys. Res. Letts., 32, L17809, doi:10.1029/2005GL023396, 2005.

Livesey, N., Filipiak, M., Froidevaux, L., Read, W., Lambert, A., Santee, M., Jiang, J., Pumphrey, H., Waters, J., Cofield, R., Cuddy, D., Daffer, W., Drouin, B., Fuller, R., Jarnot, R., Jiang, Y., Knosp, B., Li, Q., Perun, V., Schwartz, M., Snyder, W., Stek, P., Thurstans, R., Wagner, P., Avery, M., Browell, E., Cammas, J.-P., Christensen, L., Diskin, G., Gao, R.S., Jost, H.-J., Loewenstein, M., Lopez, J., Nedelec, P., Osterman, G., Sachse, G., and Webster, C.: Validation of Aura Microwave Limb Sounder O3 and CO observations in the upper troposphere and lower stratosphere, J. Geophys. Res., 113, D15S02, doi:10.1029/2007JD008805, 2008.

Luo, Y., Manson, A. H., Meek, C. E., Meyer, C. K., and Forbes, J. M.: The quasi 16-day oscillation in the mesosphere and lower thermosphere at Saskatoon $\left(52^{\circ} \mathrm{N}, 107^{\circ} \mathrm{W}\right), 1980-1996$, J. Geophys. Res., 195, 2125-2138, 2000.

Luo, Y., Manson, A. H., Meek, C. E., Thayaparan, T., MacDougall, J., and Hocking, W. K.: The 16-day wave in the mesosphere and the lower thermosphere: simultaneous observations at Saskatoon $\left(52^{\circ} \mathrm{N}, 107^{\circ} \mathrm{W}\right)$, London $\left(43^{\circ} \mathrm{N}, 81^{\circ} \mathrm{W}\right)$, Canada, J. Atmos. and Solar-Terr. Phys., 64, 1287-1307, 2002a.

Luo, Y., Manson, A. H., Meek, C. E., Meyer, C. K., Burrage, M. D., Fritts, D. C., Hall, C. M., Hocking, W. K., MacDougall, J., Riggin, D. M., and Vincent, R. A.: The 16-day planetary waves: multi-MF radar observations from the arctic to equator and comparisions with the HRDI measurements and the GSWM modeling results, Ann. Geophys., 20, 691-709, doi:10.5194/angeo-20691-2002, 2002b.

Manson, A. H. and Meek, C. E.: Small-scale features in the middle atmosphere wind field at Saskatoon, Canada $\left(52^{\circ} \mathrm{N}, 107^{\circ} \mathrm{W}\right)$ : An analysis of MF radar data with rocket comparisons, J. Atmos. Sci., 44, 3661-3672, 1987.

Manson, A. H., Meek, C. E., Luo, Y., Hocking, W. K., MacDougall, J., Riggin, D., Fritts, D. C., and Vincent, R. A.: Modulation of gravity waves by planetary waves ( 2 and $16 \mathrm{~d}$ ): observations with the North American-Pacific MLT - MFR radar network, J. Atmos. Solar-Terr. Phys., 65, 85-104, 2003.

Manson, A. H., Meek, C. E., Chshyolkova, T., Avery, S. K., Thorsen, D., MacDougall, J. W., Hocking, W., Murayama, Y., Igarshi, K., Namboothiri, S. P., and Kishore, P.: Longitudinal and latitudinal variations in dynamic characteristics of the MLT (70$95 \mathrm{~km}$ ): a study involving the CUJO network, Ann. Geophys., 22, 347-365, doi:10.5194/angeo-22-347-2004, 2004a.

Manson, A. H., Meek, C. E., Hall, C. M., Nozawa, S., Mitchell, N. J., Pancheva, D., Singer, W., and Hoffmann, P.: Mesopause dynamics form the Scandinavian triangle of radars within the PSMOS-DATAR project, Ann. Geophys., 22, 367-386, doi:10.5194/acp-8-6365-2004, 2004b.

McDonald, A. J., Hibbins, R. E., and Jarvis, J. M.: Properties of the quasi-16 day wave derived from EOS MLS observations, J. Geophys. Res., 116, D06112, doi:10.1029/2010JD014719, 2011.

Merkel, A. W., Thomas, G. E., Palo, S. E., and Bailey, S. M.: Observations of the 5-day planetary wave in PMC measurements from the Student Nitric Oxide Explorer Satellite, Geophys. Res. Lett., 30, 1196, doi:10.1029/2002GL016524, 2003.

Merkel, A. W., Garcia, R. R., Bailey, S. M., and Russell III, J. M.: Observational studies of planetary waves in PMCs and mesospheric temperature measured by SNOE and SABER, J. Geophys. Res., 113, D14202, doi:10.1029/2007JD009396, 2008.

Mitchell, N. J., Williams, P., Beard, A., Buesnel, G., and Muller, H.: Non-linear planetary tidal wave interactions in the lower thermosphere observed by meteor radar, Ann. Geophys., 14, 364-366, doi:10.5194/angeo-14-364-1996, 1996.

Mitchell, N. J., Middleton, H. R., Beard, A. G., Williams, P. J. S., and Muller, H. G.: The 16-day planetary wave in the mesosphere and lower thermosphere, Ann. Geophys., 17, 1447-1456, doi:10.5194/angeo-17-1447-1999, 1999.

Miyahara, S. and Forbes, M.: Interactions between gravity waves and the diurnal tide in the mesosphere and lower thermosphere, J. Meteorol. Soc. Jpn., 69, 523-531, 1991.

Morris, R. J., Klekociuk, A. R., and Holdsworth, D. A.: Low latitude 2-day planetary wave impact on austral polar mesopause temperatures: revealed by a January diminution in PMSE above Davis, Antarctica, Geophys. Res. Lett., 36, L11807, doi:10.1029/2009GL037817, 2009.

Nakamura, T., Fritts, D. C., Isler, J. R., Tsuda, T., Vincent, R. A., and Reid, M.: Short-period fluctuations of the diurnal tide observed with low-latitude MF and meteor radars during CADRE: Evidence for gravity wave/tidal interactions, J. Geophys. Res.Atmos., 102, 26225-26238, 1997.

Nielsen, K., Siskind, D. E., Eckermann, S. D., Hoppel, K. W., Coy, L., McCormack, J. P., Benze, S., Randall, C. E., and Hervig, M. E.: Seasonal variation of the quasi 5-day planetary wave: Causes and consequences for polar mesospheric cloud variability in 2007, J. Geophys. Res., 115, D18111, doi:10.1029/2009JD012676, 2010.

Palo, S., Roble, R., and Hagan, M.: Middle atmosphere effects of the quasi-two-day wave determined from a General Circulation Model, Earth Planet. Space, 51, 629-647, 1999.

Pancheva, D., Mitchell, N., and Younger, P.: Meteor radar observations of atmospheric waves in the equatorial mesopshere/lower thermosphere over Ascension Island, Ann. Geophys., 22, $387-$ 404, doi:10.5194/angeo-22-387-2004, 2004.

Plane, J. M. C., Cox, R. . M., and Rollason, R. . J.: Meatallic layers in the mesopause and lower thermosphere region, Advances Space Res., 24, 1559-1570, 1999.

Plumb, R. A., Heres, W., Neu, J. L., Mahowald, N. M., Corral, J., Toon, G. C., Ray, E., Moore, F., and Andrews, A. E.: Global tracer modelling during SOLVE: High-altitude descent and mixing, J. Geophys. Res., 107, 8309, doi:10.1029/2001JD001023, 2002.

Portnyagin, Y., Solovjova, T., Merzlyakov, E., Forbes, J., Palo, S., Ortland, D., Hocking, W., MacDougall, J., Thayaparan, T., Manson, A., Meek, C., Hoffmann, P., Singer, W., Mitchell, N., Pancheva, D., Igarashi, K., Murayama, Y., Jacobi, C., Kuerschner, D., Fahrutdinova, A., Korotyshkin, D., Clark, R., Taylor, 
M., Franke, S., Fritts, D., Tsuda, T., Nakamura, T., Gurubaran, S., Rajaram, R., Vincent, R., Kovalam, S., Batista, P., Poole, G., Malinga, S., Fraser, G., Murphy, D., Riggin, D., Aso, T., and Tsutsumi, M.: Mesosphere/lower thermosphere prevailing wind model, Adv. Space Res., 34, 1755-1762, 2004.

Rajaram, R. and Gurubaran, S.: Seasonal variabilities of lowlatitude mesospheric winds, Ann. Geophys., 16, 197-204, doi:10.5194/angeo-16-197-1998, 1998.

Riggin, D. M., Lui, H.-L., Lieberman, R. S., Roble, R. G., Russell III, J. M., Mertens, C. J., Mlynczak, M. G., Pancheva, D., Franke, S. J., Murayama, Y., Manson, A. H., Meek, C. E., and Vincent, R. A.: Observations of the 5-day wave in the mesosphere and lower thermosphere, J. Atmos. Solar-Terr. Phys., 68, 323-339, 2006.

Roper, R. G. and Berkey, F. T.: Mesospheric and lower thermospheric turbulence over Bear Lake, Utah, 1999-2003, J. Atmos. Solar-Terr. Phys., 73, 921-924, 2011.

Salby, M. L.: Rossby Normal Modes in Nonuniform Background Configurations. Part I: Simple fields, J. Atmos. Sci., 38, 18031826, 1981a.

Salby, M. L.: Rossby Normal Modes in Nonuniform Background Configurations. Part II: Equinox and Solstice Conditions, J. Atmos. Sci., 38, 1827-1840, 1981 b.

Sandford, D. J., Beldon, C. L., Hibbins, R. E., and Mitchell, N. J.: Dynamics of the Antarctic and Arctic mesosphere and lower thermosphere - Part 1: Mean winds, Atmos. Chem. Phys., 10, 10273-10289, doi:10.5194/acp-10-10273-2010, 2010.

Schwartz, M. J., Lambert, A., Manney, G. L., Read, W. G., Livesey, N. J., Froidevaux, L., Ao, C. O., Bernath, P. F., Boone, C. D., Cofield, R. E., Daffer, W. H., Drouin, B. J., Fetzer, E. J., Fuller, R. A., Jarnot, R. F., Jiang, J. H., Jiang, Y. B., Knosp, B. W., Krüger, K., Li, J.-L. F., Mlynczak, M. G., Pawson, S., III, J. M. R., Santee, M. L., Snyder, W. V., Stek, P. C., Thurstans, R. P., Tompkins, A. M., Wagner, P. A., Walker, K. A., Waters, J. W., and Wu, D. L.: Validation of the Aura Microwave Limb Sounder temperature and geopotential height measurements, J. Geophys. Res., 113, D15S11, doi:10.1029/2007JD008783, 2008.
Sharma, A. K., Rokade, M. V., Kondala Roa, R., Gurubaran, S., and Patil, P. T.: Comparative study of MLT mean winds using MF radars located at $16.8 \mathrm{~N}$ and 8.7 N, J. Earth Syst. Sci., 119, 461-470, 2010.

Smith, A. K.: The origins of stationary planetary waves in the upper mesosphere, Am. Meteorol. Soc., 3033-3041, 2003.

Smith, A. K.: Physics and Chemistry of the mesopause region, J. Atmos. and Solar-Terr. Phys., 66, 839-857, 2004.

Swinbank, R. and Ortland, D. A.: Compilation of wind data for the Upper Atmosphere Research Satellite (UARS) Reference Atmosphere Project, J. Geophys. Res., 108, D194615, doi:10.1029/2002JD003135, 2003.

Teitelbaum, H. and Vial, F.: On tidal variability induced by nonlinear interaction with planetary waves, J. Geophys. Res., 96, 14169-14178, 1991.

Thayaparan, T., Hocking, W. H., and MacDougall, J.: Observational evidence of tidal/gravity wave interactions using the UWO 2 MHz radar, Geophys. Res. Lett., 22, 373-376, 1995.

Torrence, C. and Compo, G.: A practical guide to wavelet analysis, Am. Meterol. Soc., 79, 61-78, 1998.

Williams, C. R. and Avery, S. K.: Analysis of long-period waves using the mesosphere-stratosphere-troposphere radar at poker flats, Alaska, J. Geophys. Res., 97, 20855-20861, 1992.

Wu, D. L., Hays, P. B., and Skinner, W. R.: A least-squares method for spectral-analysis of space-time series, J. Atmos. Sci., 52, 3501-3511, 1995.

Yuan, T., She, C.-Y., Krueger, D. A., Sassi, F., Garcia, R., Roble, R. G., Liu, H.-L., and Schmidt, H.: Climatology of mesopause region temperature, zonal wind, and meridional wind over Fort Collins, Colorado $\left(41^{\circ} \mathrm{N}, 105^{\circ} \mathrm{W}\right)$, and comparison with model simulations, J. Geophys. Res., 113, D03105, doi:10.1029/2007JD008697, 2008. 